\title{
Applications of deep learning for multimedia
}

C Springer Science+Business Media, LLC, part of Springer Nature 2020

Multimedia Tools and Applications gratefully acknowledges the editorial work of the scholars listed below on the special issue entitled "Applications of Deep Learning for Multimedia" (SI $1100)$.

Of 98 papers submitted to this issue, 15 were eventually accepted after a stringent peer review process.

\section{Corresponding Guest Editor}

\section{Dr Steven Lawrence Fernandes}

University of Alabama at Birmingham, USA

Email: stevenlf@uab.edu

\section{Guest Editors}

Dr Hong Lin

University of Houston Downtown, Texas, USA

Email: linh@uhd.edu

\section{Dr Roshan Joy Martis}

Vivekananda College of Engineering \& Technology, India

Email: roshaniiitsmst@gmail.com

\section{Dr Aminul Islam}

University of Louisiana at Lafayette, USA

Email: aminul@louisiana.edu

Publisher's note Springer Nature remains neutral with regard to jurisdictional claims in published maps and institutional affiliations. 